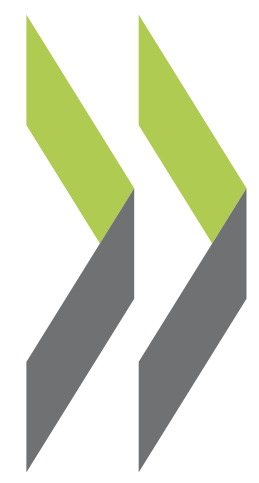

PEB Exchange, Programme on Educational Building 2005/14

\title{
An Urban Renewal School \\ Project in Italy
}

\author{
Giorgio Ponti
}

https://dx.doi.org/10.1787/541703883656 


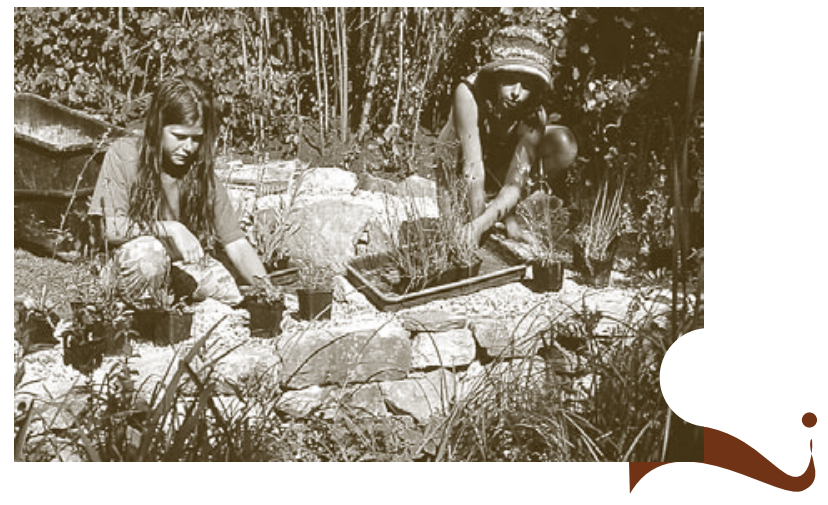

More information on "Current Concerns for Austrian School Facilities" can be found in PEB Exchange no. 49, June 2003.

ÖISS would welcome comments on these school grounds directives. Please write to Karin Schwarz, e-mail: schwarz@oeiss.org.

8. School grounds should be designed to accommodate celebrations, exhibitions, performances and similar events.

9. School grounds should comprise areas suitable for change and for new interpretation by future generations of students and teachers. The planned elements should leave room for further development.

10. The users should have possibilities to observe and experience nature.

11. Mobile equipment is a useful element for flexible school grounds, and appropriate storage facilities should be included in the design.

\section{Ecological objectives}

1. The existing vegetation should be retained if possible.

2. The possibility of re-using existing building materials and the existing substratum should be studied (reducing costs for transport, materials and disposal).

3. Rainwater should stay on the property and should be used if possible.

4. When possible, vegetation should be planted to cover roofs and façades (to reduce dust, moisture damage and noise; to provide insulation; and to provide natural habitats).

5. Maintenance does not have to be large-scale, rather it should be in harmony with nature.

6. Plants should be chosen according to the local habitat, and native species should be given priority.

More details and a checklist on planning measures can be found in the study "school:FREE"; ${ }^{2}$ additional studies and publications on this topic are available in German at www.schulfreiraum.com.

2. Mellauner, Michl and Liette Clees (ed.) (2004), "school:FREE - Recommendations for the Design of School grounds", a study carried out on behalf of ÖISS, BIG (Federal Real Estate Company) and the Austrian Federal Ministry for Education, Science and Culture (BMBWK) by the Institute of Landscape Architecture, Department for Space, Landscape and Infrastructure of the Universität für Bodenkultur (University of Natural Resources and Applied Life Sciences), Vienna. Available at www.oeiss.org., in English and German.

\section{AN URBAN RENEWAL SCHOOL PROJECT IN ITALY}

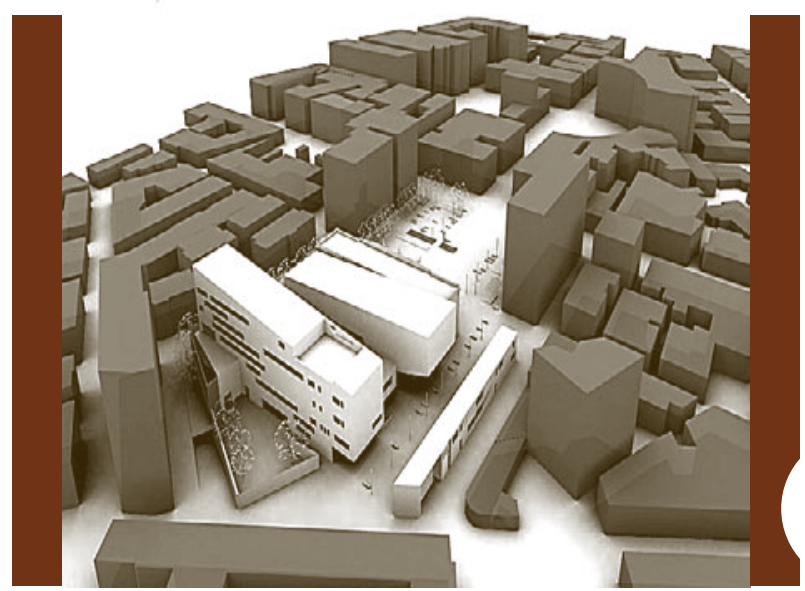

The restoration of an historic school building in Battipaglia, Italy, will provide new public facilities and is hoped to boost urban renewal. The municipality of Battipaglia, in the province of Salerno, held an architectural competition for renovating the E. De Amicis Primary School and the surrounding area. The winning project, submitted by a group of Italian architects headed by Alfredo Amati, offers four main points of interest:

- The use of a school building to promote broader urban renewal.

- The integrated planning of various services within a multifunctional architectural complex.

- High architectural quality.

- Flexibility and versatility.

The project is based on a comprehensive concept for the urban and architectural renewal of the area around the E. De Amicis School. Authorities hope the project will launch a process of linking together the adjacent existing buildings into a unified neighbourhood. 
The E. De Amicis School, one of Battipaglia's few buildings of historic significance, will be restored to its original form. The restoration is aimed at preserving part of the city's historic heritage and promoting community identity.

The school faces a square which is the symbolic hub of the architectural project. The square has been redesigned so as to highlight its role as an open urban public space, in an otherwise densely built-up area. The space is organised into various functional and formal areas to provide attractive places where people can meet and congregate.

Three additional buildings housing public facilities will be constructed behind the restored building: a convention centre/auditorium, a library and media centre, and a new classroom building. The new buildings will be functionally autonomous: they can be used simultaneously or independently, by the school or by the public, as circumstances require.

The new constructions will be similar in size and shape to the existing building, but grow successively taller, presenting new façades and perspectives. Their design echoes the symmetry and monumentality of the main façade of the old school while at the same time contrasting with it, giving the project a contemporary look.

Because of the complexity of road traffic within the city, current traffic flows have been carefully assessed so that streets can be relocated along the perimeter of the new complex. A large pedestrian area will be created, without adversely affecting vehicle traffic.

The project constitutes a dynamic public space which will meet the community's present requirements, while the planned buildings will also have the flexibility to be adapted to changing needs.

\section{Project specifications:}

Gross surface area of construction: $18000 \mathrm{~m}^{2}$ Site area: $10200 \mathrm{~m}^{2}$ Overall volume: $55000 \mathrm{~m}^{3}$ Estimated cost:

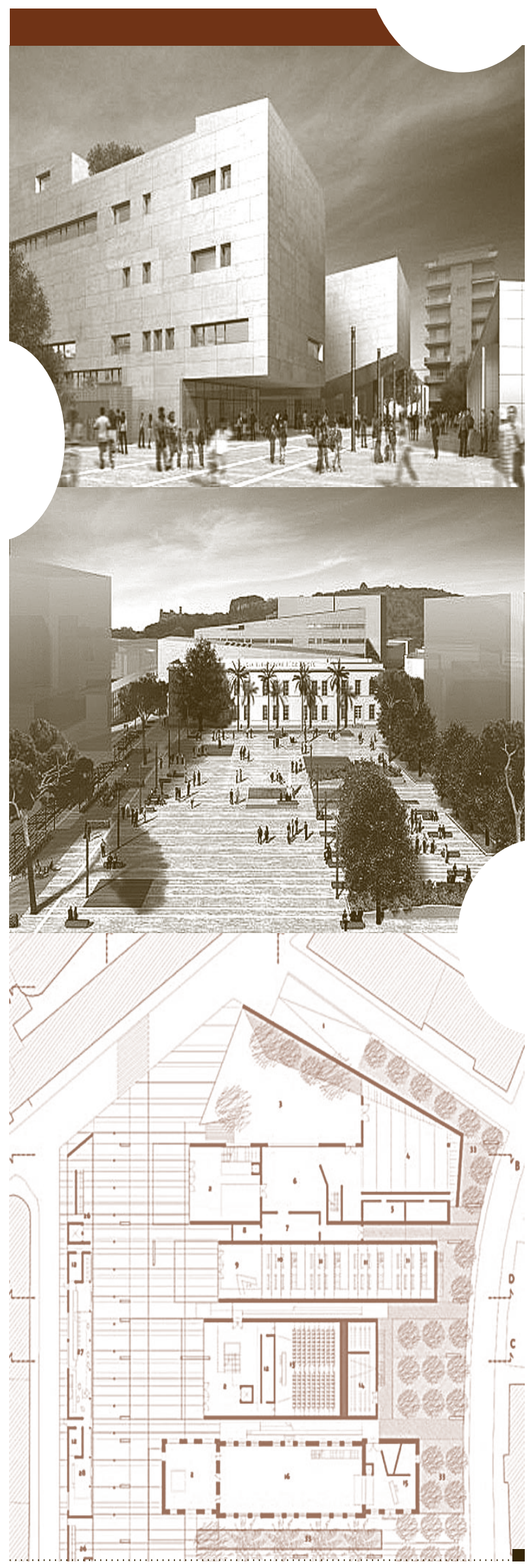

For more information, contact:

Giorgio Ponti

Co-ordinator, Educational Architecture, CISEM

Milan, Italy

Fax: 390277404166

E-mail: gio.ponti@tiscali.it 